\title{
Analysis of Gait Patterns in Individuals with Autism Spectrum Disorder After Recreational Therapy Program at Eskisehir Technical University
}

\author{
Barış Gürol ${ }^{1}$ \\ ${ }^{1}$ Faculty of Sports Sciences, Eskişehir Technical University, Turkey \\ Correspondence: Barış Gürol, Faculty of Sports Sciences, Eskişehir Technical University, Eskisehir, Turkey.
}

Received: June 15, 2019

Accepted: July 30, 2019

Online Published: October 25, 2019

doi:10.5539/ies.v12n11p105

URL: https://doi.org/10.5539/ies.v12n11p105

\begin{abstract}
The aim of the present study was to investigate the effects of adapted recreational therapy program on gait patterns of children with autism. The current study included twenty-one autistic boys aged between 8 and 15 years. The scores of the children with Autism spectrum disorder (ASD) according to the "Gilliam Autism Rating Scale-2-Turkish Version" (autism level) ranged between 62 and 123. The gait analyses of the participants were evaluated with the results of total distance, average velocity, average horizontal force and average vertical force before and after recreational therapy program. The recreational therapy program was performed throughout 12 weeks, two sessions per a week and one hour per session as the one-to-one training format. The program covered several gross motor skills such as balance, toys ball, jump, jogging to increase cardiorespiratory endurance, and several branches of the basic sports skills such as basketball, badminton, and soccer. Pearson Correlation analysis was performed in order to determine the correlation between autism level and gait parameters. A negatively significant correlation was found between autism level and average velocity $\left(\mathrm{r}=-.553^{* *}, \mathrm{p}<0.05\right)$, and also autism level and distance $\left(\mathrm{r}=-.551^{* *}, \mathrm{p}<0.05\right)$. Paired Sample $\mathrm{t}$ test was applied in order to determine if there was a change between the pre-test and post-test results of gait pattern tests. At the end of the study when pre and post test evaluation results were compared significant differences were not found in gait analysis patterns $(p<0.05)$ Recreational therapy program, which is more long term and more number of weekly sessions, should be scheduled for children and adolescents with ASD.
\end{abstract}

Keywords: autism spectrum disorder, gait analysis, recreational therapy program

\section{Introduction}

Autism spectrum disorder (ASD) is a type of mental disorder that can be observed in a set of difficulties in mutual social communication and interaction, restricted and repeated behaviours, interests and activities (APA, 2013). In other words; autism spectrum disorder is a neurodevelopmental abnormality that shows itself by means of deficiencies in social communication and interactions and repeated and restricted behaviours (National Autism Center, 2015). Individuals with ASD can have abnormalities such as not talking or talking in an unusual way, having difficulty in building relationships with their peers or having various addictions and obsessions (Kırcaali-İftar, 2013). ASD can also reveal itself with symptoms such as starting a conversation to satisfy urgent needs only, attention deficit, not sharing success or happiness, inadequate or restricted use of gestures, deficiencies in social interest or behaviours. Besides, another developmental problem seen in ASD is the repeated behaviours and restricted interests. Individuals with this disorder may have issues such as intensive repetitive behaviour patterns, adaptation to the changing environment or circumstances, overdependence on objects or people and maintaining order (National Autism Center, 2015; Schreibman, 2007).

Motor skill refers to the learned and goal-oriented movements of one or more body parts voluntarily (Gallahue, Ozmun, \& Goodway, 2014). That is to say, in order for a movement to be considered as a motor skill, it should be desired and serve a specific goal. Motor skill can be discussed and conceptualised in two ways, as tasks and proficiency in performing a movement. In the task perspective, there is an objective to achieve the movement goal. As for the proficiency perspective, the quality of the movement matters (Schmidt \& Wrisberg, 2012). Movement skill is goal-oriented and seen as the success in achieving this goal. For example, movement skill is observed as the production of 5 successful outcomes out of 10 ball throws. However, motor skills cannot be observed directly, they 
appear as a result of movement skills. For example, the test of heel toe walking administered to the individual in order to observe the "balance" motor skill is an example for this inference (Staples \& Reid, 2010).

Motor lags were detected in the motor coordination, body control and imitation skills and applications in children with ASD (Bhat et al., 2011). In addition to these, motor deficits were also observed in motor skill areas such as collective skills, hand skills and balancing (Whyatt \& Craig, 2011). Children with ASD experience serious lags in basic movement skills. These individuals, falling behind their peers of the same age group, also fall behind in basic movement skills developmentally and mentally. Their development remains deficient, thus causing them to lag behind their peers in terms of motor proficiency (Staples \& Reid, 2010; Pan, 2014).

The walking disturbances in toddlers with ASD are consistent with previous studies from Rinehart et al. (2006) in older children. These individuals describe abnormal gait features as far as coordination, smoothness and consistency.

The aim of this study was to determine the relationship between gait patterns analysis and autism level of individuals with ASD.

There are several studies within the body of literature demonstrating the effects of adapted physical activity or exercise on the motor skills and physical adaptability in children or youth with autism spectrum disorder. Apart from these, there are also studies directly revealing the situations of the individuals without the implantation of any program.

Liu and Breslin (2013) stated that children with ASD, compared to their peers who show normal development, have motor deficits in terms of motor skills such as hand skills, collective skills, static and dynamic balancing (Liu \& Breslin, 2013). Vernazza-Martin et al. (2005) investigated walking differences between autistic children and healthy children. The data show that the stride duration, mean velocity, frequency, and oscillatory and support phases were similar in both autistic and healthy children.

According to the results of the study conducted by Dewey et al., (2007), the groups diagnosed with ASD, or developmental coordination disorders and/or attention deficit, hyperactive disorder are more deficient in terms of motor skills than their peers who show normal development (Dewey, Cantell \& Crawford, 2007). The aim of the study conducted by Staples and Reid, (2010) was to compare the children with ASD to the chronological age group, developmental age group and mental age group. At the end of the study, the individuals with ASD obtained much lower scores than the chronological age group, and received similar scores to the group approximately half their age and also had much lower scores compared to the mental age group. As a result of the study, it was suggested that children with ASD had deficits in addition to delays in motor skills (Staples \& Reid, 2010). As a result of the study conducted by Pan (2014) on male teenagers in puberty with and without ASD, the researcher emphasised that the teenagers diagnosed with ASD be subjected to special procedures aimed at motor proficiency and physical adaptability (Pan, 2014).

The objective of the study performed by Todd and Reid (2006) was to analyse the snowshoeing and walking/jogging development of 3 individuals, aged 15, 16 and 20, diagnosed with ASD by applying the intervention approach. The participants joined a 6-month exercise program in open air outside the school. Within the exercise program, the design that determined the intervention approach that best suited the changing circumstances was used. The exercise program was continued with snowshoeing practice between January and March and following the end of the snow season, the practice was maintained with walking/jogging exercise. During the education process of the exercise program, the participants used a self-observation approach which included applying a sticker with a happy smile on it on a schema after the exercise. The individual reaching a certain number of stickers was given edible reinforcements (a small candy). Verbal instructions and verbal reinforcements were used by the therapist during the exercise. At the end of the study, there was an increase in the snowshoeing and walking/jogging distances of the participants, and a decrease, on the contrary, in the verbal supports and reinforcements. The research revealed that intervention approaches can increase the sustainable physical activity participation of individuals with ASD and thus the individuals can maintain more active lives (Todd \& Reid, 2006).

The aim of the study conducted by Pitetti et al. (2007) was to determine the efficiency of 9-month treadmill exercise on children with ASD. In the study, the efficiency was defined as reductions occurring in the body mass index of the participant with the increase in walking frequency, velocity, incline and monthly calorie burn of the participant on the treadmill. A total of 10 individuals, 6 males and 4 females, diagnosed with ASD participated in the study. The ages of the participants varied between 14 and 19 years. At the outset of the study, the treadmill protocol of the participants was changed in line with four factors. The first one of these was to adjust the amount of walking, which was two times a week at the beginning of the study, in a way to add one more day every other week 
with the maximum being 5 days per week. The second one was to adjust the initial 8-minute period for the participants in each session in a way to increase by 1-2 minutes every 2-3 weeks with the maximum being 20 minutes per session. The third one was to increase the velocity of the treadmill, which was between $2.4 \mathrm{mph}$ (miles per hour) and $3.5 \mathrm{mph}$, by $1 \mathrm{mph}-3 \mathrm{mph}$ every 23 weeks, with the maximum velocity remaining between 3.7 mph-4.1 mph. The fourth factor was to start the incline of the treadmill at $0 \%$ and increase up to $5 \%$. As a result of the study, reductions occurred in the body mass index of the participant with the increase in the usage, velocity, incline of the treadmill and monthly calorie burn of the participant. It was observed that the implementation of treadmill exercise on individuals with ASD could help burn of the calories and lead to reductions in the body mass index (Pietti et al., 2007).

\section{Methods}

\subsection{Subjects}

Table 1. Descriptive statistics of the children with ASD

\begin{tabular}{lc}
\hline $\mathrm{n}=21$ & mean $\pm \mathrm{sd}$ \\
\hline Age $($ year) & $11.57 \pm 2.16$ \\
Height $(\mathrm{cm})$ & $145.03 \pm 12.11$ \\
Body weight $(\mathrm{kg})$ & $45.27 \pm 14.00$ \\
BMI $\left(\mathrm{kg} / \mathrm{m}^{2}\right)$ & $21.18 \pm 5.70$ \\
\hline
\end{tabular}

$\mathrm{BMI}=$ Body mass index

The children and teenagers participating in the study within the scope of the research were selected among the individuals diagnosed with ASD. All of the participants continue their education in a school offering special education. The study was completed with 21 male participants. The ages of the participants ranged between 8 and 15. The research aimed to investigate the effect of adapted physical education and sports participation on the motor performance and physical adaptability levels of children and teenagers with ASD. The program covered several gross motor skills such as balance, toys ball, jump, jogging to increase cardiorespiratory endurance, and several branches of the basic sports skills such as basketball, badminton, and soccer. It has been concluded that previously applied adapted physical education and sports program in Turkey, improve the level of performance and physical fitness levels (Yanardağ, Ergun, Yılmaz, Aras, \& Konukman 2011; Yanardağ, Akmanoğlu, \& Yılmaz 2012). The scores of the children with ASD according to the "Gilliam Autism Rating Scale-2-Turkish Version" (Diken, Ardıç, Diken, \& Gilliam, 2012) ranged between 62 and 123. The measurement of horizontal and vertical forces produced during the stage of walking was performed using non-motorized treadmill (Woodway Force 3.0 Woodway Inc, Waukesha, USA). The gait analyses of the participants were evaluated with the results of total distance, average velocity, average horizontal force and average vertical force. For statistical calculations, the subjects' values in 1-minute walking test were evaluated. After collecting information about the gait patterns of the children with ASD, the participants were ensured to perform physical education and do sports for 1 hour each day 2 days a week for a period of 12 weeks in the sports halls of Anadolu University Faculty of Sport Sciences and later, the gait pattern analyses were repeated and their progress levels were tracked.

\subsection{Anthropometric Measurements}

The body weights of the participants were measured using an electronic laboratory scale (Seca, Vogel, \& Halke, Hamburg) in bare feet and with merely shorts on. The height measurements of the participants (Holtain Ltd, UK) were performed using a fixed stadiometer as the subjects were standing in an upright position and the chest in anatomical position, adjusted in a way to touch on the caliper heads sliding up and down the scale, whereupon the height was recorded. After the height and body weight were recorded as two measurements, their average was used for statistics.

\subsection{Data Analysis}

SPSS 21 (IBM SPSS Statistics 21, IBM Corp., USA) program was used for the statistical analysis of the data. The average and standard deviation of the data of children with ASD was calculated. Paired Sample $t$ test was applied in order to determine if there was a change between the pre-test and post-test results of gait pattern tests. The significance level of the test results was selected as $p \leq 0.05$ while the extreme significance level was selected as $\mathrm{p} \leq 0.01$ (Alpar, 2012). Pearson Correlation analysis was performed in order to determine the correlation between autism levels and gait parameters. Besides, Cohen's effect size was also determined as a result of the analyses. 
Cohen's standardized effect size index, $d$ value, indicates the quantity of the standard deviations from the averages compared. Regardless of the sign (positive-negative), $\mathrm{d}$ values, which are $.2, .5$ and .8 , can be interpreted respectively as small, medium and large effect sizes.

\section{Results}

Table 2. Gait analysis correlation table

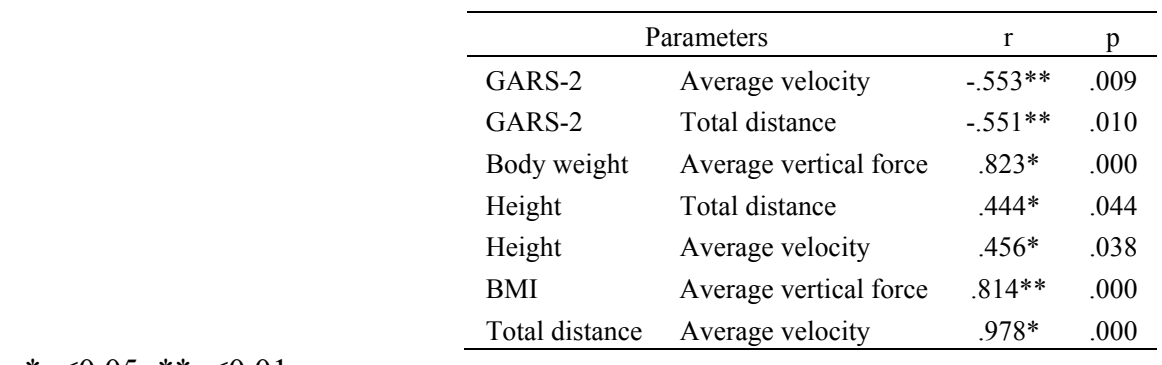

$* \mathrm{p} \leq 0.05 ; * * \mathrm{p} \leq 0.01$.

GARS-2: Gilliam Autism Rating Scale-2-Turkish Version; BMI: Body mass index.

A negatively significant correlation was found between autism level and average velocity $\left(\mathrm{r}=-.553^{* *}, \mathrm{p}<0.05\right)$, and also autism level and distance $\left(\mathrm{r}=-.551^{* *}, \mathrm{p}<0.05\right)$. A positively significant correlation was found between body weight and average vertical force $\left(\mathrm{r}=.823^{* *}, \mathrm{p}<0.05\right)$, height and distance $\left(\mathrm{r}=.444^{*}, \mathrm{p}<0.05\right)$, height and average velocity $\left(\mathrm{r}=.456^{*}, \mathrm{p}<0.05\right)$ and body mass index and average vertical force $\left(\mathrm{r}=.814^{* *}, \mathrm{p}<0.05\right)$. A positively significant correlation was found between total walking distance and average velocity $\left(\mathrm{r}=.978^{* *}, \mathrm{p}<0.05\right)$.

Table 3. Gait analysis average, standart deviation, degrees of freedom, percentage of variation, difference and effect size

\begin{tabular}{|c|c|c|c|c|c|c|}
\hline $\mathrm{n}=21$ & $\begin{array}{c}\text { Gait analysis } \\
\text { pre-test }\end{array}$ & $\begin{array}{c}\text { Gait analysis } \\
\text { post-test }\end{array}$ & \multirow[t]{2}{*}{ s.d. } & \multirow[t]{2}{*}{$\mathrm{t}$} & \multirow[t]{2}{*}{$\mathrm{p}$} & \multirow[t]{2}{*}{$\mathrm{d}$} \\
\hline & mean \pm sd & mean \pm sd & & & & \\
\hline Total distance (m) & $29.53 \pm 10.60$ & $35.69 \pm 13.69$ & 20 & -1.915 & 0.070 & 0.42 \\
\hline Average velocity (m/sn) & $0.48 \pm 0.18$ & $0.58 \pm 0.24$ & 20 & -1.708 & 0.103 & 0.36 \\
\hline Average horizontal force $(\mathrm{N})$ & $19.29 \pm 16.56$ & $41.80 \pm 52.11$ & 20 & -1.859 & 0.078 & 0.41 \\
\hline Average vertical force $(\mathrm{N})$ & $428.11 \pm 133.25$ & $447.28 \pm 171.20$ & 20 & -0.847 & 0.407 & 0.18 \\
\hline
\end{tabular}

There was not a statistically significant difference between pre and post tests values of the gait analysis $(\mathrm{p} \leq 0.05)$.

\section{Discussion and Conclusions}

Motor skill is not a diagnosis criterion for children with ASD. Nevertheless, motor skill can be one of the problems accompanying the diagnoses in children with ASD. Unusual motor deficits such as gait abnormalities and clumsiness can be given as an example for this (APA, 2013).

Adapted physical activity is the name given to the programs individualized for special people by bringing together physical and motor compliance, fundamental motor skills and routines (Winnick, 2005). Motor performance components are stability, locomotor and object control skill. As a result, gait parameters within the scope of locomotor skill among the motor performance components were evaluated in this research.

Integration of the motor skills in compliance with the exercise program of the individual starting from the early stages will support the motor development, sensory stages and physical activity level (Liu, 2013; MacDonald, Lord, \& Ulrich, 2013). Motor development can be influenced by several factors such as the relationship status between the child and the family, the games that the child plays as well as the activities the child prefers, the child's method of spending the time during his/her stay in the school and level of social participation (Gallahue et al., 2014; Pan, 2008, 2009). As can be understood from this point of view, motor development is closely connected with the children's lifestyle and daily life as well as the activities they participate/do or do not during these stages. 
The purpose of the study conducted by MacDonald et al. (2013) was to determine the correlation between the motor skills and social communication skills of the children with ASD aged between 6 and 15. As a result of the research which included 35 school-age children diagnosed with ASD, several deficits were found in the motor performance and social communication skills of the children with ASD. Besides, it was observed that as the motor performance decreased, there were more deficits in social communication skills. Just the contrary, as the motor performance increased, there were fewer deficits in social communication skills (MacDonald et al., 2013). It is thought that this study and our study provided advantages in the same direction.

There are only a few studies investigating the differences in gait patterns and abnormal walking patters of individuals with ASD. For this reason, there is a tremendous need for studies to be conducted on the analyses of gait patterns from individuals of different age groups and who are affected from ASD on different levels.

It can be said that especially step cadence, hip and ankle kinetics and kinematics cause gait abnormalities in individuals with ASD, and besides, they also perform less plantar flexor movements, have increased dorsiflexion angles depending on hypotonia and perform low hip extensor movements, and have slower walking velocity as well as smaller step length. Individual gait evaluation is of vital importance in order to develop an exercise treatment for children with ASD. In terms of recreational therapy, gait pattern analyses enable us to gain insight into the characteristic gait patterns and problems of children with ASD.

The evaluation of gait parameters in line with autism levels is thought to be beneficial for the determination of physical activity profile of children with ASD and for the improvement of their gait functions.

In conclusion, recreational therapy program, which is more long term and more number of weekly sessions, should be scheduled for children and adolescents with ASD. The effects of adapted physical education and sports program on gait patterns in autistic children should be investigated using more subjects. This study enabled an extension to the repertory of leisure skills, enhanced motor skills and provided an opportunity for social integration in a community-based sports setting for children with ASD. Individuals with ASD can be successful in practicing physical activity skills and they can improve social skills as well.

\section{References}

Alpar, R. (2012). Spor, sağllk ve eğitim bilimlerinden örneklerle uygulamalt istatistik ve geçerlik-güvenirlik. Ankara: Detay Yayıncilık

American Psychiatric Association. (2013). Diagnostic and statistical manual of mental disorders (5th ed.) (DSM-V), America, Washington, DC: American Psychiatric Publishing. https://doi.org/10.1176/appi.books.9780890425596

Bhat, A. N., Landa, R. J., \& Galloway, J. C. (2011). Current perspectives on motor functioning in infants, children, and adult with autism spectrum disorders. Journal of the American Physical Therapy Association, 91, 1116-1129. https://doi.org/10.2522/ptj.20100294

Breslin, C. M., \& Rudisill M. E. (2013). Relationships among assessment time, time on task, and motor skill performance in children with autism spectrum disorder. Adapted Physical Activity Quarterly, 30, 338-350. https://doi.org/10.1123/apaq.30.4.338

Dewey, D., Cantell, M., \& Crawford, S. G. (2007). Motor and gestural performance in children with autism spectrum disorders, developmental coordination disorder, and or attention deficit hyperactivity disorder. Journal of the International Neuropsychological Society, 13, 246-256. https://doi.org/10.1017/S1355617707070270

Diken, I. H., Ardic, A., Diken, O., \& Gilliam, J. E. (2012). Exploring validity and reliability of Turkish Version of Gilliam Autism Rating Scale-2. Education and Science, 37(166), 318-328.

Gallahue, D. L., Ozmun J. C., \& Goodway J. D. (2014). Motor gelişimi anlamak bebekler, çocuklar, ergenler, yetişkinler (Çev. Ed. Sevimay Özer, D. Ve Aktop, A.). Ankara: Nobel Yayınc1lık.

Kırcaali-İftar, G. (2013). Otizm spektrum bozukluğuna genel bakış. E. Tekin-İftar (Ed.), Otizm spektrum bozukluğu olan çocuklar ve eğitimleri içinde (2. Baskı). Ankara: Vize Yayıncılık.

Liu, T. (2013). Sensory processing and motor skill performance in elementary school children with autism spectrum disorder. Perceptual \& Motor Skills: Physical Development \& Measurement, 1, 197-209. https://doi.org/10.2466/10.25.PMS.116.1.197-209

Liu, T., \& Breslin, C. M. (2013). Fine and gross motor performance of the MABC-2 by children with autism spectrum disorder and typically developing children. Research in Autism Spectrum Disorder, 7(10), 
1244-1249. https://doi.org/10.1016/j.rasd.2013.07.002

MacDonald, M., Lord, C., Ulrich, D. (2013). The relationship of motor skills and social communicative skills in school-aged children with autism spectrum disorder. Adapted Physical Activity Quarterly, 30, 271-282. https://doi.org/10.1123/apaq.30.3.271

National Autism Center. (2015). Findings and conclusions: National Standards Project, Phase 2. Massachusetts.

Pan, C.-Y. (2008). Objectively measured physical activity between children with autism spectrum disorders and children without disabilities during inclusive recess settings in Taiwan. Journal of Autism and Developmental Disorders, 38, 2192-1301. https://doi.org/10.1007/s10803-007-0518-6

Pan, C.-Y. (2009). Age, social engagement, and physical activity in children with autism spectrum disorders. Research in Autism Spectrum Disorder, 3, 22-31. https://doi.org/10.1016/j.rasd.2008.03.002

Pan, C.-Y. (2014). Motor proficiency and physical fitness in adolescent males with and without autism spectrum disorders. Autism, 18(2), 156-165. https://doi.org/10.1177/1362361312458597

Pitetti, K. H., Rendoff, A. D., Grover, T., \& Beets, M. W. (2007). The efficacy of a 9-month treadmill walking program on the exercise capacity and weight reduction for adolescents with severe autism. Journal of Autism and Developmental Disorders, 37(6), 997-1006. https://doi.org/10.1007/s10803-006-0238-3

Rinehart, N. J., Tonge, B. J., Iansek, R., McGinley, J., Brereton, A. V., \& Enticott, P. (2006). Gait function in newly diagnosed children with autism: cerebellar and basal ganglia related motor disorder. Dev Med Child Neurol, 48, 819-824. https://doi.org/10.1111/j.1469-8749.2006.tb01229.x

Rinehart, N. J., Tonge, B. J., Bradshaw, J. L., Iansek, R., Enticott, P. G., \& Johnson, K. A. (2006). Movement-related potentials in highfunctioning autism and Asperger's disorder. Dev Med Child Neurol, 48, 272-277. https://doi.org/10.1017/S0012162206000594

Schmidt, R. A., \& Wrisberg, C. A. (2012). Motor öğrenme ve performans (Çev. Ed. Ziya Koruç). Ankara: Anı Yayıncilik.

Schreibman, L. (2007). The science and fiction of autism. Cambridge, Harvard University Press.

Staples, K. L., \& Reid, G. (2010). Fundemental movement skills and autism spectrum disorders. Journal of Autism and Developmental Disorders, 40, 209-217. https://doi.org/10.1007/s10803-009-0854-9

Todd, T., \& Reid, G. (2006). Increasing physical activity in individuals with autism. Focus on Autism and Other Developmental Disabilities, 21(3), 167-176. https://doi.org/10.1177/10883576060210030501

Vernazza-Martin, S., Martin, N., Vernazza, A., Lepellec-Muller, A., Rufo, M., Massion, J., \& Assaiante, C. (2005). Goal Directed Locomotion and Balance Control in Autistic Children. Journal of Autism and Developmental Disorders, 35(1), 91-102. https://doi.org/10.1007/s10803-004-1037-3

Whyatt, C. P., \& Craig, C. M. (2012). Motor skills in children Aged 7-10 years, diagnosed with autism spectrum disorder. Journal of Autism and Developmental Disorders, 42, 1799-1809. https://doi.org/10.1007/s10803-011-1421-8

Winnick, J. P. (2005). Adapted Physical Education and Sport. Champaign IL: Human Kinetics.

Winnick, J. P., \& Short, F. X. (1999). Brockport physical fitness test manual: A health related assessment for youngsters with disabilities (2nd ed.). Champaign, IL: Human Kinetics.

Yanardağ, M., Akmanoğlu, N., \& Yılmaz, I. (2012). The effectiveness of video prompting on teaching aquatic play skills for children with autism. Disability and Rehabilitation, 35(1), 47-56. https://doi.org/10.3109/09638288.2012.687030

Yanardağ, M., Ergun, N., Yılmaz, I., Aras, O., \& Konukman, F. (2011). Effects of pool exercise training on stereotypical behavaiors in autism. Research Quarterly for Exercise and Sport, 82(1), 76-84.

\section{Copyrights}

Copyright for this article is retained by the author(s), with first publication rights granted to the journal.

This is an open-access article distributed under the terms and conditions of the Creative Commons Attribution license (http://creativecommons.org/licenses/by/4.0/). 